Resumo

Este artigo traz um estudo da obra inicial de Lacan, na qual se rompe com o estudo das psicoses pela psiquiatria tradicional, e nos interessa no ponto em que tal ruptura nos mostra a originalidade dos caminhos iniciais de Lacan com o esquema do estádio do espelho. Inicialmente, a teorização lacaniana desenvolve-se agregando o campo da personalidade aos estudos da psicose, definindo os fenômenos paranoicos em suas relações de compreensão. Essa perspectiva só se torna possível na medida em que Lacan opera um avanço teórico, ao fazer uma distinção entre a ordem genética e a gnosiológica no homem. Descritores: psicanálise; Lacan; estádio do espelho; paranoia.

\section{A ORIGINALIDADE E A ORIGEM DO ESTÁDIO DO ESPELHO EM LACAN}

DOl: http://dx.doi.org/10.11606/issn. 1981-1624.v19i3p465-481

Jussara Falek

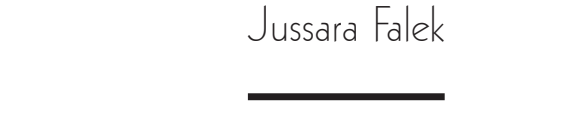

$\Lambda$ Y

osso estudo sobre o esquema do estádio do espelho em Lacan começa por sua obra inicial - a tese de doutorado em medicina "Da psicose paranoica e suas relações com a personalidade", publicada em 1932 - na qual podemos notar uma ruptura no que concerne naquele momento ao estudo das psicoses pela psiquiatria tradicional, e interessa-nos no ponto em que tal ruptura mostra a originalidade dos caminhos iniciais que Lacan empreendeu no seu ensino acerca da técnica e teoria psicanalíticas.

$\mathrm{O}$ título de sua tese já figura a originalidade e a ruptura da obra lacaniana. Ambos qualitativos aqui se mesclam, na medida em que a originalidade de Lacan dá-se ao passo da ruptura com as conceituações de toda uma psiquiatria acerca dos fenômenos na paranoia em sua base mais fundamental, uma vez que introduz no estudo desse campo as relações de compreensão pertinentes aos fenômenos da personalidade.

- Psicólogo. Mestrando em Psicologia Clínica pelo Instituto de Psicologia da Universidade de São Paulo (IPUSP), São Paulo, SP, Brasil.

- a Psicanalista. Membro da École Lacaniènne de Psychanalyse e docente do Instituto de Psicologia da Universidade de São Paulo (IPUSP), São Paulo, SP, Brasil. 
Em sua extensa revisão bibliográfica, Lacan (1987) aponta-nos que o campo da alienação mental era dividido em dois grandes grupos: o da demência precoce e o da psicose. Nos estudos sobre a demência, apontava-se uma forte correlação desta enfermidade com fatores orgânicos, o que fundamentava uma noção de paralelismo entre as manifestações psíquicas, as quais seriam causadas por lesões ou alterações orgânicas respectivas. Tratando-se da psicose, em contraste com esse primeiro grupo, não se ressaltava essa correlação orgânica direta nas manifestações sintomáticas; assim, os estudos desses casos tratavam de distúrbios tidos como psicogênicos, dada a razão que:

na ausência de qualquer déficit detectável pelas provas de capacidade (de memória, de motricidade, de percepção, de orientação e de discurso), e na ausência de qualquer lesão orgânica apenas provável, existem distúrbios mentais que relacionados, segundo as doutrinas, à "afetividade", ao "juízo", à "conduta", são todos eles distúrbios específicos da síntese psíquica. (Lacan, 1987, p. 2)

Essa concepção da psicose acarreta um grande problema na medida em que não se sabe sobre a dinâmica que assume a síntese psíquica nestes casos, problema que vai se estender à nosografia da paranoia. Lacan, em seu texto "Structure des psychoses paranoïaques" (1931), nos diz que:

A concepção da paranoia que herdou ao mesmo tempo das velhas monomanias e dos fundamentos somáticos à noção de degeneração agrupou nela estados psicopáticos decerto muito diversos. Ela tem, entretanto, a vantagem de evocar um terreno, base não psicogênica de todos estes estados. Mas o progresso da clínica, Kraepelin, os italianos, Sérieux et Capgras, isolaram-na sucessivamente dos estados paranoides ligados à demência precoce, das psicoses alucinatórias crônicas, enfim, dessas formas mais ou menos transitórias de delírios que constituem a paranoia aguda e que deviam entrar em quadros variados desde os acessos delirantes polimorfos até os estados pré-demenciais passando pela confusão mental. (tradução nossa)

Assim, no que se refere à paranoia, dentro do grande campo da alienação mental, pode-se dizer que esta se constitui sofrendo as consequências desses dois grandes grupos iniciais. E os mesmos estudos que permitiram sua maior delimitação conceitual não solucionaram o problema inicial que recaiu sobre todo o campo da psicose, a saber, o enigma da sua característica síntese psíquica.

A tese lacaniana de 1932 presta-se a lançar luzes no que de enigmático, de irracional e de desrazão continha o estudo acerca dos fenômenos paranoicos. Segundo Lacan, essa obscuridade devia-se à ausência de uma teorização que pudesse dizer sobre a síntese psíquica nesses casos. 
E, para ele, essa síntese será senão, em sua tese, a própria personalidade.

Dessa forma, constitui-se uma teoria que reconhece nos sintomas mórbidos da paranoia, por mais anômalos que pareçam, a manifestação de uma tendência concreta ${ }^{1}$ que pode ser, em certa medida, inteligível e definida em relações de compreensão humana. Essa perspectiva que dá um novo status aos fenômenos da paranoia só torna-se possível na medida em que Lacan opera um avanço teórico, ao fazer uma distinção entre aquilo que, no homem, seria da ordem de sua própria gênese, enquanto humano, em referência àquilo que seria, nesse mesmo homem, de uma ordem gnoseológica, ou seja, da ordem do conhecimento humano. Assim, para ele, toda a confusão gerada pela doutrina psiquiátrica era consequência de situar o problema da paranoia como genético, enquanto, na verdade, seria um problema da ordem do conhecimento humano, como o do eu enquanto sujeito do conhecimento. Pode-se dizer que é nesse ponto que reside a originalidade de sua tese e a genialidade de Lacan em abordar a psicose paranoica.

Essa nova perspectiva nos estudos da paranoia, em contradição expressa com os estudos de seu mestre Clérambault, faz Lacan aproximar-se da doutrina psicanalítica, sendo que em sua tese temos uma das primeiras exposições acerca dessa aproximação com Freud. Como o próprio Lacan diz, a sua pesquisa sobre as psicoses objetiva dar prosseguimento ao estudo psicanalítico naquilo mesmo em que este tem encontrado barreiras ao seu avanço (1987). Por conseguinte, uma das primeiras incursões de Lacan como propriamente teórico da psicanálise pode ser vista como consequência das problemáticas apontadas nos estudos da psicose.

\section{A introdução do esquema do estádio do espelho}

O esquema do estádio do espelho que Lacan apresentou quatro anos após a sua tese, em julho de 1936, no congresso psicanalítico de Marienbad, é tido como o primeiro pivô de sua intervenção na teoria psicanalítica, e podemos ver aí, além do narcisismo, as elaborações iniciais de Lacan no que concerne à questão problemática do eu na teoria analítica freudiana.

Considerando a produção escrita, a primeira referência ao estádio do espelho consta em um texto produzido por Lacan para a Encyclopédie française, intitulado "Os complexos familiares na formação do indivíduo”, em 1938. É sobre ela que nos debruçaremos inicialmente. A relevância do estudo que Lacan apresenta, nesse seu texto, revela-se como uma reiteração do caráter essencial do seu posicionamento na pesquisa em psicanálise, considerando o objeto estudado - no referido texto, a família - em seu condicionamento por fatores culturais, reconhecendo que o essencial à ordem humana é a 
subversão da fixidez instintiva, à qual, nos animais, adere-se.

A exceção humana deve ser explicada por sua expressiva impotência biológica nos primeiros anos de vida em relação aos demais animais, de tal forma que, segundo Lacan, não se deve hesitar em considerar que a criança na primeira idade encontrarse-ia em um estado de prematuração biológica fatal se não ficasse sob cuidados de um outro (Lacan, 2003).

A contraposição ao instinto, como um suporte orgânico regulador das funções vitais, será, segundo esse texto de Lacan, dada pela função que os complexos exercem que, diante da expressiva insuficiência maturacional no homem, substituem a insuficiência congênita dessas funções pela regulação, através da imago, de uma função social. No entanto, percebamos que:

Ao opor o complexo ao instinto, não negamos ao complexo todo e qualquer fundamento biológico, e, ao defini-lo por certas relações ideais, nós o ligamos a sua base material. Essa base é a função que ele assegura no grupo social, e esse fundamento biológico pode ser visto na dependência vital do indivíduo em relação ao grupo. (Lacan, 2003, p. 40)

Mas, de qualquer forma, Lacan foge do preconceito biologista uma vez que o complexo, próprio ao psiquismo humano, não responde às funções vitais, mas à insuficiência congênita destas funções através do apelo ao outro. Esse é o recurso 
teórico por meio do qual vemos Lacan desenvolver seu percurso inicial como teórico da psicanálise.

Como não poderia ser diferente, nesse texto vemos a elaboração teórica do Eu seguir nessa mesma linha de conceituação, a qual leva em consideração os complexos como organizadores do desenvolvimento psíquico humano e, especificamente, deste em sua relação social, ou seja, em sua relação com o outro. Para tanto, é o "complexo de intrusão" que servirá de base para a função da identificação na constituição do eu.

Esse complexo de intrusão pode ser comprovado na observação experimental de crianças e nas investigações no campo da psicanálise, principalmente, referentes à situação de rivalidade entre irmãos; mas, de um modo geral, ocorre entre as crianças em certa idade intervalar.

A novidade dos estudos que Lacan apresenta em seu texto está na descoberta de que a relação de rivalidade estabelecida entre os infantes manifestava, na verdade, uma identificação mental com o outro, o semelhante. Esse fenômeno da identificação mental ocorre nas crianças entre 6 meses e 2 anos de idade, sendo deixadas sozinhas e à espontaneidade lúdica. Entre as reações observadas, reconhece-se objetivamente essa relação definida pela rivalidade:

comporta com efeito entre os sujeitos uma certa adaptação das posturas e dos gestos, qual seja, uma conformidade em sua alternância e uma convergência em sua sucessáo, que os ordenam como provocaçóes e respostas e permitem afirmar, sem prejulgar a consciência dos sujeitos, que eles discernem a situação como tendo uma saída dupla, como uma alternativa. (Lacan, 2003, p. 43)

Tais observações indicam que na medida em que há uma adequação do comportamento de uma criança com a outra, podemos admitir que há o reconhecimento do outro como rival, o que revela o reconhecimento do outro como objeto. Contudo, para que este efeito seja observado tem-se que respeitar uma diferença etária específica entre as crianças; caso contrário, as reações serão distintas e aparecerão atitudes como exibição, sedução e despotismo etc., ou seja, em vez de uma relação conflitiva entre dois, como no primeiro enquadramento, ter-se-á "um conflito entre duas atitudes opostas e complementares, e essa participação bipolar é constitutiva da própria situação" (Lacan, 2003, p. 44). Mas o que essa última configuração confirma de mais paradoxal é que, de fato, cada parceiro confunde a parte do outro com a sua própria e identifica-se com ele; assim, não se sabe quem estaria exercendo o papel do sedutor e o do seduzido, 
chegando, muitas vezes, a manifestar comportamentos discordantes entre si. $\mathrm{O}$ mais significativo, nesse caso, em relação à primeira situação, centra-se no fato de que cada uma das crianças pode viver a sua situação sozinha, sem a necessidade de uma participação efetiva do outro.

Com isso, Lacan conclui que "nesse estágio, a identificação, específica das condutas sociais, baseia-se num sentimento do outro, que só pode ser desconhecido sem uma concepção correta de seu valor inteiramente imaginário" (Lacan, 2003, p.44). Percebemos isso na medida em que para ocorrer uma "real" interação entre as crianças, como na primeira situação, é condição necessária uma semelhança maturacional significativa entre os sujeitos considerados. Evidenciando que só assim ocorre essa identificação mental com o rival na medida em que "a imago do outro parece estar ligada à estrutura do corpo próprio, e, mais especialmente, de suas funções de relação, por certa similitude objetiva" (Lacan, 2003, p. 44). Essa conclusão nos dá o simulacro do que Lacan vai desenvolver em sua teoria do estádio do espelho que, neste caso, irá tratar da imagem do corpo próprio.

É em meio a essas elaborações sobre o estágio de desenvolvimento da criança que a concepção do estádio do espelho se aplica. Lacan esclarece-nos que

A identificação afetiva é uma função psíquica cuja originalidade a psicanálise estabeleceu, especialmente no complexo de Édipo.... Mas o emprego desse termo, na etapa que estamos estudando, é mal definido na doutrina; foi isso que tentamos suprir com uma teoria da identificação cujo momento genético designamos pela denominação de estádio do espelho. (Lacan, 2003, p. 46)

Mais especificamente, esse estádio irá corresponder ao declínio do desmame, por volta do fim dos 6 meses, no qual a criança sofre do mal-estar psíquico correspondente ao atraso de sua maturação fisiológica, que, para Lacan, é a base do desmame no homem.

Ora, o reconhecimento pelo sujeito da sua imagem no espelho é um fenômeno que, para a análise desse estágio, é duplamente significativo: o fenômeno aparece depois de seis meses e o seu estudo, nesse momento, re; vela demonstrativamente as tendências que então constituem a realidade do sujeito; a imagem especular, justamente em razão destas afinidades, fornece um bom símbolo desta realidade: de seu valor afetivo, tão ilusório quanto a imagem, e de sua estrutura, que, como ela, é reflexo da forma humana. (Lacan, 2003, p. 47) 
No entanto, no ser humano, o fascínio pela imagem especular corresponde a um determinado período que predominaria por volta do fim do primeiro ano; neste período, a inteligência instrumental humana equivale-se à do chimpanzé, o que justificaria a semelhança do comportamento lúdico para com a própria imagem vista entre as duas espécies, se restringirmos o humano a essa faixa etária. Assim, a partir desse momento, vemos outra forma de relação do homem com a própria imagem, fenômeno que teve seu início desde os 6 meses de vida e agora assume outras características, como bem descreve-nos Lacan:

característica de uma intuição iluminante, ou seja, contra o fundo de uma inibição atenta, súbita revelação do comportamento adaptado (aqui, um gesto de referência a uma parte do corpo), seguida pelo esbanjamento jubilatório de energia que assinala objetivamente o triunfo, numa dupla reação que deixa entrever o sentimento de compreensão, em sua forma inefável. (Lacan, 2003, p.47)

Esse novo momento da relação do bebê com a sua própria imagem seria resultado do investimento libidinal que adentraria nesse estádio e que, para Lacan, teria sua fonte nas condições em que o filhote humano encontra-se submetido após o seu nascimento. Assim,

Essas condiçôes [libidinais] são apenas as tensões psíquicas provenientes dos meses de prematuração, e que parecem traduzir uma dupla ruptura vital: a ruptura da adaptaçáo imediata ao meio, que define o mundo animal por sua conaturalidade, e a ruptura da unidade de funcionamento do ser vivo, que, no animal, submete a percepçáo à pulsão. (Lacan, 2003, p. 47)

Em outras palavras, esse investimento libidinal na imagem que apresenta um ideal de unidade para o sujeito ocorre devido ao nascimento do bebê humano em condições ainda insuficientes para a sua sobrevivência, em termos de falta de coordenação, tanto das pulsões quanto das funções orgânicas. Veremos assim, nesse novo momento, um estádio afetivo e mentalmente constituído a partir de uma percepção do corpo próprio como fragmentado, mas que se percebe em movimentos diferentes:

por um lado, o interesse psíquico encontra-se deslocado para as tendências que visam a uma recolagem do corpo próprio; por outro lado, a realidade, inicialmente submetida a um despedaçamento perceptivo cujo caos atinge até suas categorias - por exemplo, "espaços" tâo díspares quanto as sucessivas 
posiçôes estáticas da criança -, ordena-se refletindo as formas do corpo, que fornecem como que o modelo de todos os objetos. (Lacan, 2003, p.48)

Como podemos perceber, o mundo narcísico próprio dessa fase não se explica apenas pelo investimento libidinal no próprio corpo, como também se refere à estrutura mental, e Lacan o frisa no sentido mais próprio do mito de Narciso: "quer esse sentido indique a morte - a insuficiência vital de que proveio esse mundo -, quer a reflexão especular - a imago do duplo que lhe é central -, quer, ainda, a ilusão da imagem - este mundo, como veremos, não contém o outro" (Lacan, 1939, p. 48).

$\mathrm{O}$ que fica claro com esse estudo sobre esse estádio no homem é que a busca humana por uma unidade mental encontra seu respaldo intuitivamente na imagem especular, reconhecida como ideal da imago do duplo. O duplo que se constitui com a imagem especular vem dizer sobre a tendência externa própria à formação do eu. Lacan designa essa intromissão da imagem como uma intrusão narcísica, uma vez que antes da afirmação de uma identidade, é necessário que o eu aliene-se nessa imagem que o forma nesse momento original. E Lacan ressalva ainda que as marcas dessa intrusão primordial permanecerão.

o eu guardará dessa origem a estrutura ambígua do espetáculo, que, evidenciada nas situaçóes anteriormente descritas de despotismo, sedução e exibição, dá forma às pulsóes sadomasoquista $\mathrm{e}$ escopofílica (desejo de ver e de ser visto), que são essencialmente destruidoras do outro. (Lacan, 2003, p. 49)

Não restam dúvidas com relação às contribuições desse texto de Lacan para esclarecimentos sobre a sua incursão inicial no campo da psicanálise, e a mais importante que temos, nesta produção, segue na referência que faz à concepção do Eu $(I c h)$ na teoria de Freud e à elaboração inicial que tece sobre ela. Para o psicanalista francês, a concepção freudiana do Eu, ao designá-la como um "sistema de relações psíquicas segundo o qual o sujeito subordina a realidade à percepção consciente" (Lacan, 2003, p.77), é insuficiente, principalmente ao se contrastar com as experiências clínicas da psicanálise que denunciam a importância nesse sistema das projeções do Ideal do Eu que, "desde as imagens de grandeza... até as fantasias que polarizam o desejo sexual e a ilusão de vontade de poder, manifesta nas formas imaginárias do eu uma condição não menos estrutural da realidade humana" (Lacan, 2003, p. 78).

Vemos essa concepção freudiana, à qual Lacan tece sua crítica, espee cialmente no texto "O Eu e o Id", de 1923. Ao longo desse texto, Freud busca desenvolver sua investigação a partir das relações que o eu estabeleceria com as percepções, sejam elas externas (mundo externo ao indivíduo) ou, em termos dinâmicos, 
oriundas do sistema Ics (mundo interno), de tal modo que o indivíduo, nas palavras de Freud, seria concebido como:

um Id psíquico, irreconhecido e inconsciente, em cuja superfície se acha o Eu, desenvolvido com base no sistema Pcp, seu núcleo. Se buscarmos uma representaçáo gráfica, podemos acrescentar que o Eu não envolve inteiramente o Id, mas apenas à medida que o sistema Pcp forma a sua superfície [do Eu], mais ou menos como o "disco germinal" se acha sobre o ovo. O Eu não é nitidamente separado do Id; conflui com este na direção inferior. (Freud, 2011, p.31)

Como percebe-se, nesse percurso, ao esclarecer as relações entre as percepções externa e interna com o sistema perceptivoconsciente, Freud concebe o sistema perceptual como sendo o núcleo do eu. Mas, este eu, como salientamos primeiramente no que concerne a esse texto, de acordo com Freud, não se restringe à consciência, ou seja, ao sistema perceptual-consciente; haveria também nessa instancia uma parte 'inferior' que se fundiria com o Id. Em outras palavras, o reprimido também constituiria o Eu, mas destacar-se-ia dele pelas resistências da repressão egoica. Assim, segundo Freud:

o Eu é aquela parte do Id modificada pela influência direta do mundo externo, sob mediação do Pcp-Cs, como que um prosseguimento da diferenciação da superfície. Ele também se esforça em fazer valer a influência do mundo externo sobre o Id e os seus propósitos, empenha-se em colocar o princípio da realidade no lugar do princípio do prazer, que vigora irrestritamente no Id. A percepçáo tem, para o Eu, o papel que no Id cabe ao instinto. $\mathrm{O}$ Eu representa o que se pode chamar de circunspecção, em oposição ao Id, que contém as paixôes. (Freud, 2011, p.31)

Mas, mesmo para Freud, essa definição do Eu como uma instância psíquica representante do mundo externo não satisfaz conceitualmente as exigências da experiência clínica na psicanálise. Nesse momento, ele remonta à existência de uma 'gradação' superior ao Eu, que ele chama de "Ideal de Eu" e "Supereu", definidos como uma parte do Eu que seria menos vinculada à consciência. Esse passo é dado por Freud a partir dos estudos sobre a dinâmica entre o Eu e as catexias de objeto, considerando os casos em que ocorre um processo de introjeção do objeto no Eu, na medida em que a catexia objetal foi substituída por uma identificação egoica. Segundo Freud, "tal substituição participa enormemente na configuração do Eu e contribui de 
modo essencial para formar o que se denomina seu caráter' (2011, p. 35). As descobertas das experiências clínicas com os casos de melancolia dão conta desse fenômeno, na medida em que se observa nesses quadros que na perda de um objeto sexual ocorreria uma alteração egoica que, para Freud, só poderia ser descrita por uma instalação do objeto na instância do Eu. Esse mecanismo de introjeção do objeto perdido poderia facilitar o abandono desse objeto investido com as catexias do Id, de tal modo que Freud lança uma hipótese:

Talvez essa identificação seja absolutamente a condição sob a qual o Eu abandona seus objetos. De todo modo, o processo é muito frequente, sobretudo nas primeiras fases do desenvolvimento, e pode possibilitar a concepção de que o caráter do Eu é um precipitado dos investimentos objetais abandonados, de que contém a história dessas escolhas de objeto. (2011, p. 36)

Outra implicação que pode ser tirada desse processo de introjeção do objeto é que o Eu, ao assumir as características do objeto introjetado, toma-se como objeto de amor do Id: uma forma compensatória da perda sofrida por este último.

A origem do Ideal de Eu e Supereu adviriam dos efeitos das primeiras identificações ocorridas na mais primitiva infância que, segundo Freud, serão gerais e duradouras. Nesse momento, poderíamos ser levados a pensar que se trataria do mesmo mecanismo de identificação decorrente da perda de um objeto, mas, como se observa no texto freudiano, trata-se de algo diferente na origem, especificamente, do Ideal do Eu:

por trás dele [do Ideal do Eu] se esconde a primeira e mais significativa identificaçấo do indivíduo, aquela com o pai da pré-história pessoal. Esta não parece ser, à primeira vista, resultado ou consequência de um investimento objetal; é uma identificação direta, imediata, mais antiga do que qualquer investimento objetal. Mas as escolhas de objeto pertencentes ao primeiro período sexual e relativas a pai e mãe parecem resultar normalmente em tal identificação, e assim reforçar a identificação primária. (Freud, 2011, p.39)

$\mathrm{Na}$ teorização acerca do estádio do espelho, Lacan tirará consequências disso que estaria em uma ordem originária na constituição do Eu anterior à identificação característica do desfecho do complexo edípico. Mas, em continuação com a elaboração freudiana, não teremos notícias maiores sobre esse momento originário que jazeria por trás do Ideal do Eu, portanto, avançaremos nesse ponto com as teorizações lacanianas.

Segundo Lacan, essas observações à delimitação conceitual do Eu na teoria psicanalítica mostram que:

Se as instâncias psíquicas que escapam ao Eu aparecem primeiramente como efeito do recalque da sexualidade na infância, sua formação se revela, na experiência, cada vez mais próxima, quanto ao tempo e à estrutura, da situação de separação que a análise da angústia faz com

474 Estilos clin., São Paulo, v. 19, n. 3, set./dez. 2014, 465-481. 
que se reconheça como primordial, e que é a do nascimento. (Lacan, 2003, p. 78)

Dessa forma, a concepção acerca do estádio do espelho ganha todo o seu valor teórico para dizer sobre a constituição do Eu na psicanálise, uma vez que vemos, nesse momento original, a raiz do drama humano. Como Lacan demonstra-nos à luz da trama edípica:

Ela [a concepção do estádio do espelho] estende o suposto trauma dessa situação [edípica] a todo um estágio de despedaçamento funcional, determinado pelo inacabamento especial do sistema nervoso; ela reconhece, desde esse estágio, a intencionalização dessa situação em duas manifestaçóes psíquicas do sujeito: a assunção do dilaceramento original no jogo que consiste em rejeitar o objeto, e a afirmaçáo da unidade do corpo próprio na identificação com a imagem especular. (Lacan, 2003, p.78)

"O estádio do espelho como formador da função do Eu [je]" é um dos primeiros textos em que Lacan expõe de forma aberta sua teoria da constituição do Eu e confirma a distinção do je em relação ao moi, os quais concentravam na obra freudiana em um único termo a instância do Eu (Ich). Trata-se, nesse texto, de um aspecto inicial e, ao mesmo tempo, uma primeira marca de originalidade nos estudos de Lacan no campo da psicanálise. Este psicanalista já tinha dado nota disso em sua tese que, ao circunscrever o problema da paranoia à ordem gnosiológica, tece a distinção, 
no campo dos fenômenos psíquicos, entre aquilo que seria referente ao $\mathrm{Eu}$, enquanto sujeito do conhecimento humano, e o que se referiria à gênese própria do Eu. Assim, teremos esse seu texto acerca do estádio do espelho como uma elaboração para dar conta de como o Eu (je), sujeito do conhecimento, advém e sua relação com o Eu (moi), instância imaginária e originária desse próprio je.

Essa cisão terminológica do Eu não está presente, como dissemos, em Freud propriamente, tampouco nos primeiros textos de Lacan, incluindo sua tese, apesar de nesta já estar contida explicitamente uma elaboração teórica acerca do Eu que apontava para uma clivagem futura, uma vez que conceitualmente já se mostrava problemático concentrar em um único termo noções distintas e já delimitadas teoricamente. Ainda assim, coube a Lacan não só operar essa distinção terminológica, mas também elaborar teoricamente essa intersecção, o que ele o faz ao introduzir o esquema do estádio do espelho, o qual, não por acaso, destaca a imagem na constituição da função do $j e$.

Não podemos deixar de observar que o Eu (je), na experiência de análise, mostra-se contrário à proposição filosófica do cogito, de tal modo que não poderemos conceber que esse Eu alcance, tal como a proposição fundamental cartesiana, o sujeito pensante a respeito de sua própria natureza. Lacan segue outra via, e o caminho apontado pela experiência clínica da psicanálise explicita essa divergência. O estádio do espelho não só mostra a alienação à imagem especular como ponto de partida para a constituição do je, mas também diz sobre o seu destino alienante.

Lacan, em seu texto de 1948, "A agressividade em psicanálise", explora essa precisão terminológica na noção do Eu com mais evidência na medida em que questiona a concepção defendida por Freud de identificar o Ich ao núcleo do sistema percepção-consciência, a partir da qual se difunde no campo da psicanálise a noção de um Eu centrado nos parâmetros das ciências naturais e físicas. No entanto, as observações clínicas freudianas continuam sendo a base para os passos iniciais de Lacan, de tal modo que, como este último salienta, a instância do Eu a ser considerada será a reconhecida por Freud sob o aspecto da Verneinung. Assim, Lacan recoloca no centro da questão do Eu a sua essência fenomenológica muito difundida pelas observações clínicas de Freud nas "reações de oposição, ostentação, denegação e mentira, que são os modos característicos da instância do eu [moi] no diálogo" (1998a, p.111).

Lacan nos diz:

Em suma, designamos no [moi] o núcleo dado à consciência, mas opaco à reflexão, marcado por todas as ambiguidades que, da complacência à má-fé, estruturam no 
sujeito humano a vivência passional; esse [je] que, por confessar seu artificialismo à crítica existencial, opóe sua irredutível inércia de pretensóes e desconhecimento à problemática concreta da realizaçáo do sujeito. (1998a, p.112)

Neste trecho, podemos melhor nos situar em relação à delimitação desses dois termos e nos referenciarmos, ainda que lateralmente, à questão do sujeito (do inconsciente). O moi, como frisa Lacan, revela-se nas paixões da vida que, como são para todos, não se dizem muito bem em palavras ou resistem ao cogito humano. Fica evidente que esse $j e$ (que, na língua francesa, presta-se apenas a ser pronome pessoal - sujeito da frase) exerceria sua função de sujeito gramatical, mas na ignorância da efetivação do sujeito. É dessa função do je que trata Lacan, um ano depois, em sua comunicação no Congresso Internacional de Psicanálise, em Zurique, "O estádio do espelho como formador da função do eu [je] tal como nos é revelado na experiência psicanalítica".

No estádio do espelho, Lacan aponta o que não só a experiência clínica, mas também o vivencial de cada um que tem contato com crianças já pôde atestar, a saber, o fascínio que a imagem de si mesmo exerce nos primeiros anos da criança. Para Lacan:

A assunção jubilatória de sua imagem especular parecer-nos-á, pois, manifestar, numa situação exemplar, a matriz simbólica em que o eu [je] se precipita numa forma primordial, antes de se objetivar na dialética da identificação com o outro e antes que a linguagem lhe restitua, no universo, sua função de sujeito. (Lacan, 1998b, p.97)

Essa Gestalt situa a instância do eu (je) em uma linha que, segundo Lacan, se daria no nível da ficção, uma pré-história do sujeito antes mesmo do processo dialético no qual este se constitui. Essa forma (Gestalt) original será "para sempre irredutível para o indivíduo isolado - ou melhor, que só se unirá assintoticamente ao devir do sujeito, qualquer que seja o sucesso das sínteses dialéticas pelas quais ele tenha que resolver, na condição de eu (je), sua discordância de sua própria realidade" (Lacan, 1998b, p. 98).

Para Lacan, a assunção dessa imagem no sujeito deve ser tida como uma identificação, no sentido próprio dado ao termo pela psicanálise, ou seja, aquela que implica em uma transformação no sujeito. A experiência com os efeitos da imagem do corpo próprio nas crianças não difere em nada disso; na verdade, mostra-se mais reveladora dos efeitos de uma identificação como fonte do desenvolvimento infantil. Trata-se aqui de uma identificação à imagem e não de uma imitação dela. Assim, essa Gestalt antecipa uma conformação de unidade que no sujeito encontra-se ainda em estado de potência, em termos não só de sua maturação fisiológica, mas também de ordem pulsional.

Dessa forma, evidencia-se que o desenvolvimento do bebê humano 
vai decorrer em uma antecipação imaginária externa ao indivíduo que é "mais constituinte do que constituída, mas em que, acima de tudo, ela lhe aparece num relevo de estatura que a congela e numa simetria que a inverte, em oposição à turbulência de movimentos com que ele experimenta animá-la" (Lacan, 1998b, p. 98). Com a introdução do esquema do estádio do espelho, Lacan nos apresenta a apercepção espacial no homem, anterior à dialética que o constituirá como sujeito, explicitando o efeito do nascimento prematuro no bebê, no qual a imago vem estabelecer uma função deixada em aberto pela deiscência do organismo humano nos primeiros anos de vida. Para Lacan:

O estádio do espelho é um drama cujo impulso interno precipita-se da insuficiência para a antecipação - e que fabrica para o sujeito, apanhado no engodo da identificaçáo espacial, as fantasias que se sucedem desde uma imagem despedaçada do corpo até uma forma de sua totalidade que chamaremos de ortopédica - e para a armadura enfim assumida de uma identidade alienante, que mascarará com sua estrutura rígida todo o seu desenvolvimento mental. (1998b, p. 100).

Convém observar que esse estádio, apesar do termo propriamente atestar que se trata de um momento do desenvolvimento humano, também se presta como uma analogia à formação do eu (je), e Lacan a faz com suas próprias palavras:

A formação do eu [je] simboliza-se oniricamente por um campo fortificado, ou mesmo um estádio, que distribui da arena interna até sua muralha, até seu cinturão de escombros e pântanos, dois campos de luta opostos em que o sujeito se enrosca na busca do altivo e longínquo castelo interior, cuja forma (às vezes justaposta no mesmo cenário) simboliza o isso de maneira surpreendente. (Lacan, 1998b, p. 101)

Não só as formações oníricas, mas também a sintomatologia das neuroses evidenciam com clareza a concepção do sujeito na experiência por excelência de linguagem da psicanálise. Mas, segundo Lacan (1998b), elas o revelam no impensável de um sujeito absoluto, de tal forma que, através desse esquema, pode-se instituir uma ordem objetiva das gêneses das defesas do Eu.

Assim, os sintomas histéricos como paralisia, anestesia, inibição, escotomização, entre outros, que dizem de uma desintegração de uma função somaticamente localizada devem ser entendidos como a forma psíquica característica do estágio do corpo despedaçado. 
Os fenômenos psíquicos da histeria estariam entre os mais arcaicos, considerando-se a constituição do eu (je), daí sua manifestação remontar ao despedaçamento primordial no homem. Já os sintomas obsessivos (escrupulosidade, obsessão ruminante, cerimoniais, impulsos obsessivos etc.) centrar-se-iam numa dissociação das condutas organizadoras do Eu, ou seja, remontariam geneticamente a um momento posterior à histeria. A origem da neurose obsessiva estaria entre as primeiras atividades de identificação do Eu. Dessa forma, ao referir-se às neuroses de transferência, veremos que a origem está na atipia do Édipo, mas a forma do sintoma diz respeito a um momento anterior a este e originário dele.

Entretanto, o mais revelador do estudo sobre a constituição do eu (je), com a introdução do esquema do estádio do espelho, é que a paranoia, no sentido genético, estaria numa fase posterior aos quadros neuróticos. Ela, como Lacan aponta, teria sua origem no momento de passagem do eu (je) - do especular para o social. Isso quer dizer que, na paranoia, não há a resolutividade do período do estádio do espelho que inauguraria o processo dialético, o qual, por sua vez, constituiria a relação desse $\mathrm{Eu}(j e)$ às situações sociais.

A conclusão desse estádio, segundo Lacan,

É esse momento que faz todo o saber humano bascular para a mediatização pelo desejo do outro, constituir seus objetos numa equivalência abstrata pela concorrência de outrem, e que faz do Eu [je] esse aparelho para o qual qualquer impulso dos instintos será um perigo, ainda que corresponda a uma maturaçáo natural - passando desde entáo a própria normalização dessa maturação a depender, no homem, de uma intermediaçáo cultural, tal como se vê, no que tange ao objeto sexual, no complexo de Édipo." (1949/1998, p.102)

\section{Considerações finais}

Assim, nesse primeiro momento de seu ensino, com sua formulação acerca da constituição do Eu através da alienação a imagem do outro no espelho (o espelho aqui considerado como uma metáfora para o que se constituirá posteriormente como o grande Outro), Lacan teoriza, da forma como já se observara em sua Tese, que a problemática da paranoia manifestar-se-ia na gênese do Eu e precisamente deste, enquanto je (sujeito do conhecimento) que não se safaria da alienação à imagem especular, implicando o fracasso dialético, de tal forma que são nesses termos que podemos colocar os primeiros passos de Lacan no que concerne à questão da paranoia no campo da psicanálise e, sobretudo, a originalidade do estádio do espelho, significativamente ligado a essa sua teorização inicial.

Ao discorrer sobre a originalidade de Lacan no campo da psicanálise 
deparamos com um passo fundamental que não só restitui à paranoia sua expressão em termos subjetivos - ao circunscrever a problemática da paranoia ao Eu (je) - mas que também possibilita um aporte teórico-clínico inicial importante, do qual a inserção da paranoia como possibilidade clínica no campo da psicanálise é devedora. Assim, é em vista desse rigor conceitual acerca do Eu (je e moi) que novos estudos podem avançar no campo das investigações acerca da paranoia.

\section{Abstract}

THE ORIGINALITY AND THE ORIGIN OF THE MIRROR STAGE IN $L A C A N$

This paper presents a study of the early works of Lacan, in which he breaks with the study of psychosis by traditional psychiatry, which interests us at the point where such a rupture shows the originality of the initialpaths of Lacan. Initially, the Lacanian theory is developed by adding the field of personality studies to psychosis, defining the paranoid phenomena in their understanding of relationships. This perspective becomes possible only insofar as Lacan operates a theoretical advance, in making a distinction between the genesis and gnoseological orders in men.

Index terms: psychoanalysis; Lacan; the mirror stage; paranoia.

\section{RESUMEN}

LA ORIGINALIDAD Y EL ORIGEN DEL ESTADIO DEL ESPEJO DE LACAN

En este articulo se presenta un estudio de la obra lacaniana inicial, que rompe con el estudio de la psicosis por la psiquiatría tradicional, y que nos interesa en el punto donde esta ruptura muestra la originalidad de los caminhos iniciales con el esquema estadio del espejo de Lacan. Inicialmente, la teoría lacaniana se desarrolla con la agregación del campo de la personalidade en los estudios de la psicoses, definiendo asi los fenómenos paranoicos en sus relaciones de entendimiento. Esta perspectiva sólo es posible en la medida que Lacan opera un avance teórico, haciendo una distinción entre la orden de la génesis y la orden gnoseológica en el hombre.

Palabras clave: psicoanálisis; Lacan; el estadio del espejo; paranoia.

\section{REFERÊNCIAS}

Freud, S. (2011). O eu e o id. In S. Freud, O Eu e o Id, "Autobiografia" e Outros Trabalhos (P.C. Souza, trad.). São Paulo: Companhia das Letras.

Lacan, J. (1931). Structura des psychoses paranoïaques. Recuperado de http://www. ecole-lacanienne.net/documents/1931-07-07.doc.

Lacan, J. (1987). Da psicose paranóica em suas relaçōes com a personalidade (A. Menezes, M. A. C. Jorge, P. M. Silveira, trad.). Rio de Janeiro: Forense-Universitária.

Lacan, J. (2003). Os complexos familiares na formação do indivíduo. In J. Lacan, Outros Escritos (pp.29-90). Rio de Janeiro: Jorge Zahar Ed. 
Lacan, J. (1998a). Agressividade em psicanálise. In J. Lacan, Escritos (pp.104-126). Rio de Janeiro: Jorge Zahar Ed.

Lacan, J. (1998b). O estádio do espelho como formador da função do eu. In J. Lacan, Escritos (pp.96-103). Rio de Janeiro: Jorge Zahar Ed.

Lacan, J. (2007). O seminário, livro 23: o sinthoma (S. Laia, trad.; A. Telles, rev.). Rio de Janeiro: Jorge Zahar Ed.

Roudinesco, E., \& Plon, M. (1998). Dicionário de psicanálise (R. Vera, L. Magalhães, trad.; M. A. C. Jorge, superv.).Rio de Janeiro: Jorge Zahar Ed.

\section{NOTA}

1. Em sua tese, Lacan usa essa expressão para se referir ao paralelismo nos sintomas mentais que, para ele, só possuem valor positivo na medida em que estáo ligados a uma tendência concreta, isto é, "a determinado comportamento da unidade viva em face de um objeto dado" (1932, p. 346).

diofaustino@gmail.com Av. Professor Melo de Moraes, 1235, Bloco C/204 05508-030 - São Paulo - SP - Brasil.

jfalek@usp.br Avenida Arruda Botelho, 570/62 05466-000 - São Paulo - SP - Brasil.

Recebido em setembrol 2013. Aceito em de maiol 2014. 